L'architecture vivante. Le Corbusier and the Soviets Palace

PALABRAS CLAVE - EL PALACIO DE LOS SOVIETS LE CORBUSIER · L'ARCHITECTURE VIVANTE · REVISTA . PUBLICACIÓN

KEYWORDS - THE SOVIETS PALACE · LE CORBUSIER L'ARCHITECTURE VIVANTE. IOURNAL. PUBLICATION

\title{
L'architecture vivante
}

\section{Le Corbusier y el Palacio de los Soviets}

\begin{abstract}
PEDRO PONCE GREGORIO · Universidad Politécnica de Valencia · pedpongr@gmail.com IGNACIO PERIS BLAT· Universidad Politécnica de Valencia· igpebla1@pra.upv.es SALVADOR SANCHIS GISBERT · Universidad Politécnica de Valencia·salsangl@pra.upv.es
\end{abstract}

Fecha de recepción: 10 de mayo 2020 - Fecha de aceptación: 24 de noviembre 2020

EI proyecto del Palacio de los Soviets, - concluido por la oficina de Le Corbusier en diciembre de 1931, fue, sin lugar a dudas, uno de los trabajos más importantes en la vida y obra del arquitecto. Su concurso podríamos catalogarlo como uno de los hitos más relevantes en la historia de la arquitectura del siglo XX junto a otros tan célebres como el del Chicago Tribune (1922), el del Palacio del Trabajo en Moscú (1923) y el de la Sociedad de Naciones de Ginebra (1927).

Buena prueba de ello son la gran cantidad de publicaciones en las que durante treinta y tres años -desde 1932 hasta 1965 (año de su desaparición)--, el maestro decidió mostrar su palais: ya fuera a través de revistas externas, en muchas ocasiones dirigidas y editadas por amigos personales; o mediante libros propios, escritos y maquetados por él mismo. Durante este tiempo, no hubo publicación importante en la que, de un modo u otro, el palais no estuviera presente.

Así, como sucediera con otros tantos proyectos no construidos, "el papel" quedaba constituido como el único medio capaz de reconstruir los entresiijos de este palacio, y desvelar así, mediante palabras, imágenes y dibujos, algunas de las consignas más importantes del que sin duda fue uno de los grands travaux de Le Corbusier. De ahí la importancia de este proyecto de los Soviets para la publicación del quinto número de L'architecture vivante del año 1932, sacada a la luz pocas semanas más tarde de haberse concluido el trabajo, y donde, sin entrar a valorar las cuestiones más propias del proyecto de arquitectura, trataremos de describir, analizar e interpretar -y en su caso versionar y argumentaralgunas de las asociaciones de imágenes e ideas propuestas por el arquitecto entre las páginas.

De este modo, el proyecto del Palacio de los Soviets se destina aquí como un instrumento con el que demostrar la importancia material del "papel" en la obra de Le Corbusier, ya no como mecanismo eficaz de presentación, sino como materia portante de su arquitectura. Las publicaciones, ya no son para el arquitecto meros escaparates para el lucimiento o la exhibición, sino que sus páginas detentan además la posibilidad de "construir" algunas de las ideas o intenciones, tantas veces ocultas entre la inmensidad de sus proyectos.

\section{L'ARCHITECTURE VIVANTE}

Fundada por el arquitecto rumano Jean Badovici en $1923^{[1]}$, y subtitulada como "documents sur l'activité constructive dans tous

[1] Aunque también contribuyeran en su creación el crítico griego Christian Zervos (1889-1970) fundador en 1926 de la también célebre revista Cahiers d'art-y el editor francés Albert Morancé (1874-1951), sería Jean Badovici (1893-1956) el que se dedicara con mayor profusión a la crítica arquitectónica a través de L'architecture vivante. Escribió además algunos libros como Intérieurs de süe et mare (1924), Intérieurs français (1925), y Grandes constructions: béton armé, acier et verre (1931), donde la edificación industrial se mostraba como catalizadora de la nueva arquitectura. 
les pays", L'architecture vivante publicaría un total de cuarenta y dos números semestrales con los que, en palabras del propio editor, se intentaría

ofrecer la colección más amplia, más variada y más característica de documentos de la que se pueda disponer para emprender el estudio de la arquitectura contemporánea en lo que esta tenga realmente de novedoso. Estudiaremos cada obra bajo el punto de vista de su desarrollo orgánico, de los materiales que emplea, de los procesos que aplica, de las nuevas condiciones que se imponen a ella (Morancé 1923, p. 8).

Pero las directrices fundamentales de la publicación se imprimían en las contraportadas de cada uno de los números, donde se podía leer:

L'architecture vivante reproducirá edificios de arquitectos franceses o extranjeros, cuya obra constituya una demostración de los fecundos recursos del artista contemporáneo, de su claridad de espíritu, de su juicio delicado y seguro; examinará la base fundamental de una obra, es decir, la construcción y las numerosas exigencias que implica; analizará los detalles de utilidad que forman, como decía Delacroix, el punto de partida del arquitecto; buscará además la forma y el marco que la arquitectura ha sabido inventar sin violentar las leyes de la construcción, y por las que revela su sensibilidad artística; estudiará, al mismo tiempo que la estructura, las formas y la decoración arquitectónica, las artes que contribuyen al embellecimiento de un edificio, indicando con ejemplos aquel espíritu que debe reinar en la colaboración del arquitecto con el pintor o el escultor, con el fin de que la obra del constructor no sea deformada por sus producciones, tan hermosas sean adoptadas en sí mismas (Morancé 1923, contraportada).
El porqué del título quedaría reservado a Auguste Perret -sin duda, uno de los arquitectos franceses más importantes del momento-, pues es él quien en el prólogo del primer número, escribe que la arquitectura "vivante"

es aquella que expresa fielmente su época. Buscaremos ejemplos en todos los ámbitos de la construcción y elegiremos las obras que, estrictamente subordinadas a su uso y realizadas con el empleo juicioso de la materia, alcancen la belleza por las disposiciones y las proporciones armoniosas de los elementos necesarios que las componen (Morancé 1923, 5).

Adjunto a ese texto, y quién sabe si como clave introductoria de aquella primera intención, la edición transcribe en esta misma página una cita de Fedro - protagonista junto a Sócrates del célebre diálogo de Eupalinos o el arquitecto (1923) de Paul Valéry-, en la que apunta:

Dime (ya que eres tan sensible a los efectos de la Arquitectura), ¿̇no has observado, al pasearte por esta ciudad, que entre los edificios que la componen, algunos son mudos, otros hablan y otros, en fin, los más raros, cantan? No es su destino, ni siquiera su forma general lo que los anima o lo que los reduce al silencio. Eso depende del talento de su constructor, o del favor de las Musas (Morancé 1923, p. 5).

Qué duda cabe, por tanto, de la pertinencia de este proyecto de los Soviets en las páginas de L'architecture vivante, donde el palais se nos muestra y define como una obra única, repleta de sensibilidades, en la que se reúnen algunas de las ideas más profundas de su arquitecto.

\section{QUINTO NÚMERO. OTOÑO-INVIERNO DE 1932}

Si tenemos en cuenta que para Le Corbusier (y Pierre) el proyecto de los Soviets se daría por concluido el día 16 de febrero de 1932 ${ }^{[2]}$, pocas semanas debieron pasar hasta que el palais saliera publicado en el quinto número de L'architecture vivante que se dedicaba íntegramente a la obra de los arquitectos, el de otoño-invierno de 1932[3] (FIGURA 1).

Se trataba de un número monográfico en el que el palais aparecía precedido de doce páginas -básicamente escritas- donde se mostraban el "Plan de urbanización de la ciudad de Argel (1931-32)", la "Propuesta para la exposición internacional de la vivienda de París (1937)" y el "Plan de acondicionamiento de la Porte-Maillot de París (1929-30)" (Morancé 1932, 31). Al palais, en cambio, se le dedican un total de catorce páginas en las que se condensan medio centenar de imágenes, entre planos, bocetos y fotografías; el texto, por su parte, utilizado de manera abundante en los proyectos anteriores, ocupará los intersticios dejados en blanco entre las imágenes sin más intención que la de precisar algunos de los detalles mostrados por los dibujos.

Así, una vez llegamos a este punto, cabe decir que el proyecto de los Soviets comienza aquí en la página 17, justo donde aparecen una "vista de pájaro" del edificio y el alzado del "acceso a la sala A". Todo ello bajo un discreto título en el que se puede leer: "Proyecto encargado a Le Corbusier y P. Jeanneret por el Gobierno de la URSS, para estudiar la construcción de un Palacio de los Soviets en Moscú (1931)" (Morancé 1932, p. 17) (Figura 2).

[2] Recordemos que en este día concreto los arquitectos realizaron su tercer y último envío a Moscú. Trece días más tarde, esto es, el 29 de febrero, es cuando el TASS publicaría aquella célebre resolución en la que «los proyectos de los arquitectos soviéticos Zholtovsky e lofan, así como el del arquitecto estadounidense H. O. Hamilton [eran] considerados como los mejores». Véase FLC 12-5-227-(001-002). Extracto de la circular mecanografiada, publicada por el TASS el 29 de febrero de 1932.

[3] Cabe decir que fueron siete los números de L'architecture vivante dedicados a la obra de Le Corbusier y Pierre Jeanneret, los de otoño-invierno de 1927, otoño-invierno de 1929, primavera-verano de 1930, primavera-verano de 1931, otoño-invierno de 1932, otoño-invierno de 1933 y otoño-invierno de 1936. 
1. Cubierta y antecubierta de L'architecture vivante, $5^{\text {ème }}$ série. París: Éditions Albert Morancé, otoño-invierno 1932. Fuente: Morancé, Albert (Edit.). (otoño-invierno 1932). L'architecture vivante. París: Éditions Albert Morancé.

2. L'architecture vivante, $5^{\text {ème }}$ série. París: Éditions Albert Morancé, otoño-invierno 1932. pp. 17-19. Fuente: Morancé, Albert (Edit.). (otoño-invierno 1932). L'architecture vivante. París: Éditions Albert Morancé.

1
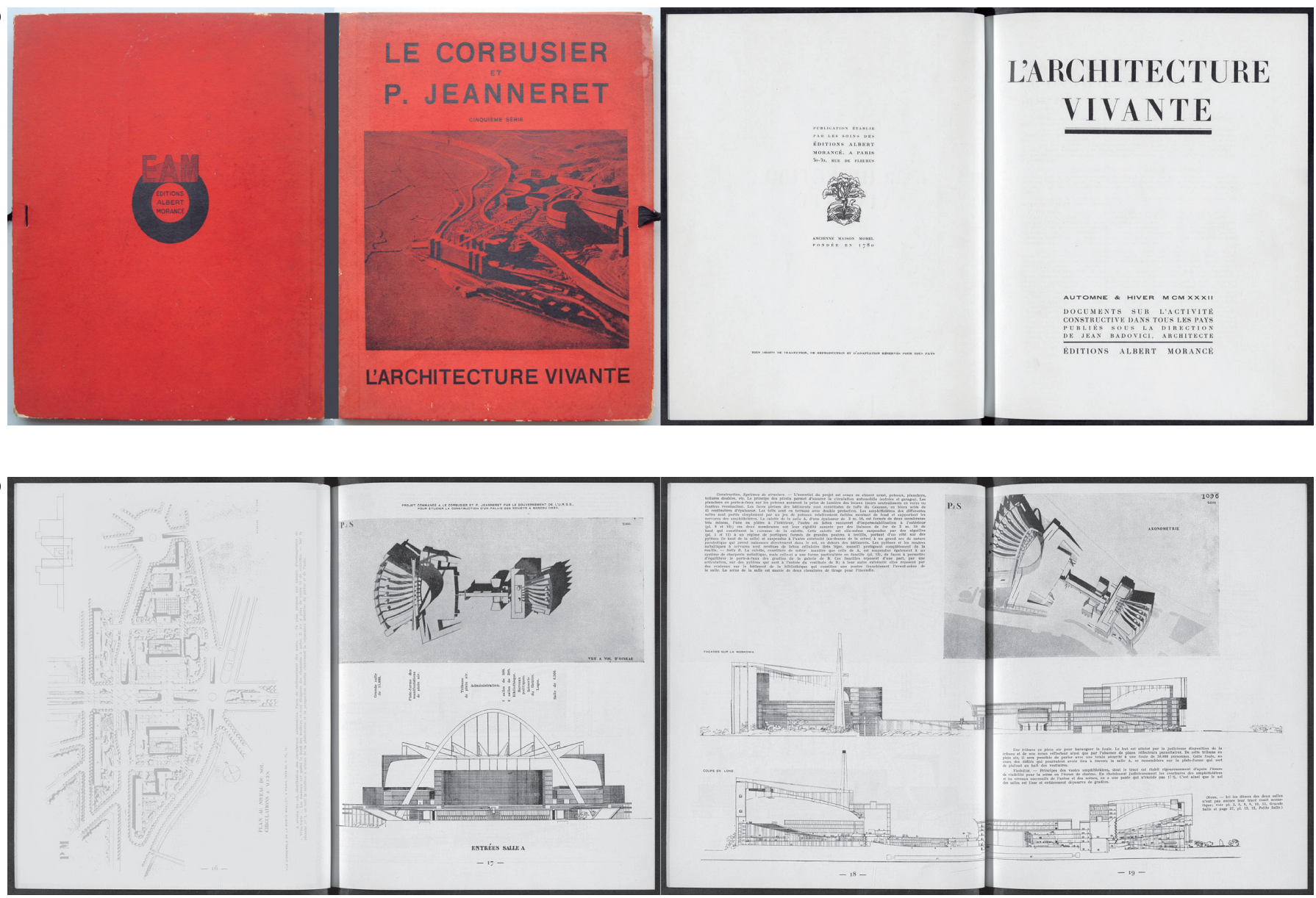

De los dos dibujos que ocupan esta primera página del palais podemos decir que si bien el alzado del margen inferior es una réplica idéntica de aquel primer dibujo de FLC 27248 -catalogado en el "Livre noir" como PdS 2815 la planta se encuentra retocada con respecto a la original de FLC 27232 -o, PdS 2808-, muy posiblemente con la intención de incorporarlo a la revista. Y es que apenas bastaba un vistazo para darnos cuenta de que la diferencia entre la una y la otra radica en el hecho de que ahora la planta del palais sí que se encuentra dibujada junto a una oscura e imponente sombra que, además de aportar profundidad a la imagen, demuestra-ahora sobre el plano del suelo- la gran expresividad formal del palais. Un artificio gráfico que los arquitectos ya tantearían en bocetos como FLC $27360^{[4]}$, muy posiblemente utilizados como previo para este nuevo dibujo definitivo.

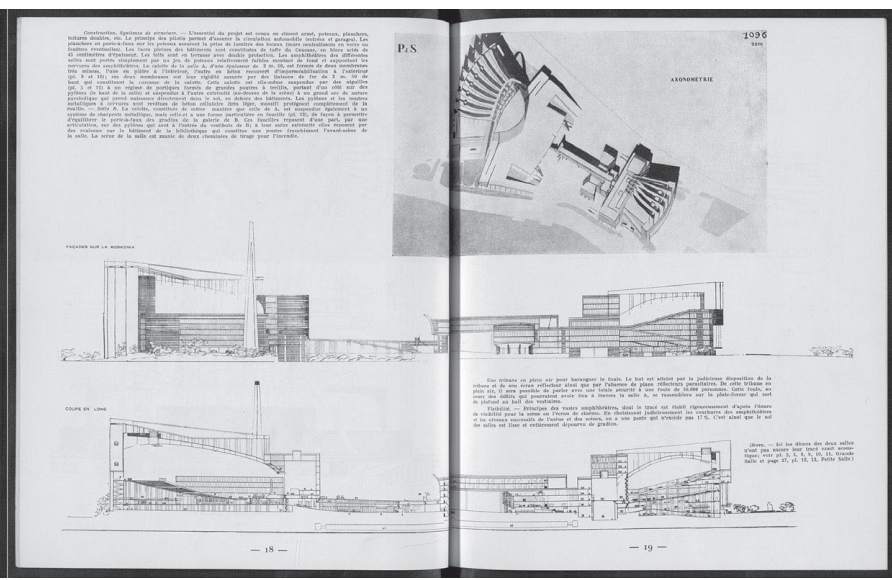

Estrategia similar se utilizará en dibujos como la axonometría de las páginas 18 y 19 donde, de nuevo retocado con respecto al original de FLC 27246 -o, PdS 2816-, el palais se nos muestra sin ningún tipo de sombra u entorno que pueda distraer la mirada atenta del jurado. Al lado de esta, en un texto extraído del capítulo séptimo de la memoria del proyecto, se puede leer:

[4] Además de en este FLC 27360, la sombra del palais también se estudia de un modo muy similar en FLC 27395 También en FLC 27281 y 27375, aunque tan solo en el conjunto de la sala B. 


\section{CONSTRUCCIÓN. SISTEMAS DE}

ESTRUCTURA. Lo esencial de nuestro proyecto está concebido en hormigón armado, pilares, forjados, cubiertas dobles, etc. El principio de los pilotis nos permite asegurar la circulación automóvil y pilotis (accesos y garaje). Los forjados en voladizo sobre los pilares aseguran la entrada de luz a los locales (muros neutralizantes de vidrio o ventanas eventuales). Las superficies macizas de los edificios están constituidas de tuffe del Cáucaso, en bloques cortados de 45 centímetros de espesor. Las cubiertas son en terraza con doble protección. Los anfiteatros de las diferentes salas están soportados únicamente por un conjunto de pilares relativamente delgados que ascienden por el fondo y soportan los nervios de los anfiteatros. La bóveda de la sala $A$, con un espesor de $2,50 \mathrm{~m}$, está formada por 2 membranas muy delgadas, una en escayola al interior, otra en hormigón recubierto de impermeabilización al exterior; estas dos membranas tienen su rigidez asegurada por barras de hierro de 2,50 m de altura que constituyen la carcasa de la bóveda. Esta bóveda está suspendida por tirantes en un sistema de pórticos formados por grandes vigas en retícula que apoyan de un lado sobre pilares (la altura de la sala) y se suspenden del otro extremo (por encima del escenario) de un gran arco de naturaleza parabólica que nace directamente del suelo, al margen de los edificios. Los pilares y las vigas metálicas nervadas están recubiertas con hormigón celular (más ligero, sólido) que las protege completamente del óxido. - Sala B. La bóveda, constituida de la misma manera que la de $A$, está suspendida igualmente de un sistema de estructura metálica, pero esta tiene una forma particular en hoz, de manera que permite equilibrar el voladizo de las gradas de la galería de B. Estas hoces apoyan por un lado, por una articulación, sobre pilares que están en el acceso del vestíbulo de $\mathrm{B}$; en su otro extremo se apoyan en cilindros sobre los edificios de la biblioteca que constituye una cercha que salva el escenario de la sala. El escenario de la sala está equipado con dos chimeneas de tiro para incendios (Morancé 1932, p. 18).

En la parte inferior de la página se observan el alzado y la sección de FLC 27242 y 27243 -o, PdS 2814 y 2813 , respectivamente- y un nuevo cuadro de texto, separado en dos párrafos, donde se transcriben algunas de las ideas recogidas en los capítulos cuarto y quinto de la memoria del proyecto:

Una tribuna al aire libre para arengar a la multitud. El objetivo se consigue por la disposición racional de la tribuna y planos reflectores dada la ausencia de planos reflectores parasitarios. Desde esta tribuna al aire libre, será posible hablar con total seguridad a una multitud de 50.000 personas. Esta multitud, durante los desfiles que podrían tener lugar a través de la sala A, se reunirá sobre la plataforma que sirve de techo al hall de los guardarropas.

VISIBILIDAD. Principio de grandes anfiteatros, cuyo trazado viene determinado estrictamente de acuerdo al diseño de visibilidad del escenario o la pantalla de cine. Eligiendo con criterio las curvaturas de los anfiteatros y los respectivos niveles de la palestra y los escenarios, se mantiene una pendiente que no supera el $17 \%$. Es así que el suelo de las salas es suave y completamente desprovisto de escalones (Morancé 1932, 19).

Las páginas 20 y 21 son, sin lugar a dudas, las más descuidadas de la publicación. Ya no solo porque no exista en ellas una composición atractiva entre cada uno de los elementos, sino porque da la sensación de que la información se dispone de un modo desordenado; a la manera de un "cajón de sastre" en el que se amalgaman algunos de los aspectos más dispares del palais: desde vistas y plantas del vestíbulo de la sala $\mathrm{A}$ a planos generales de circulación (FIGURA 03).

A partir de aquí, si comenzamos por la imagen del margen superior izquierdo, diremos que se trata de la célebre perspectiva de FLC 27251 - o, PdS 2819- en la que se muestra el gran plano inclinado que servía de acceso a la sala A. Un dibujo importante en el que se combinan-como podremos observar en el resto de perspectivas- dos tipos de trazado distintos: uno lineal, hecho a regla, para representar la arquitectura y su espacio; y otro curvo, ya a mano alzada, para reproducir los personajes que la circulan.

Bajo esta, y ocupando toda la anchura de las páginas, aparecen alineadas las tres plantas de PdS 2809 (FLC 27256, 27271 y 27233) en las que de nuevo Le Corbusier, quizás como estrategia para hacerlas más atractivas e inteligibles, arroja sombras a algunos de sus elementos; a la manera de un bajorrelieve primitivo en el que se texturizan cada una de sus siluetas.

Pero al margen de estas tres plantas sombreadas y la tan vistosa perspectiva interior, los arquitectos ubican también en esta página los tres planos de circulaciones que conformaban el PdS 2822: el primero (FLC 27237), girado $180^{\circ}$ con respecto al resto, donde se representan los "espacios reservados a los peatones", $\mathrm{O}$, dicho de otro modo, los accesos del palais; el segundo (FLC 27266), en el que se trazan los circuitos de "las comitivas al interior de la Gran Sala y al exterior sobre la plataforma de 50.000 [personas]"; y el tercero (FLC 27267), donde se reproducen "las dos redes automóviles [una de entrada y otra de salida] que comunican los distintos accesos" del edificio (Morancé 1932, p. 21).

En las siguientes dos páginas de la revista se ubica, de lado a lado, la planta de pilotis de FLC 27231 -o, PdS 2806-y un esquema en sección de las circulaciones que se detallaban en la página anterior. De hecho esta sección, representada de manera definitiva en FLC 27272, se trataba de un dibujo que también formaba parte de aquellas tres plantas de PdS 2822 en las que, como decíamos, se representaban los accesos y algunos de los circuitos - peatonales y rodados- que se daban cita sobre el palais. 
3. L'architecture vivante, $5^{\text {ème }}$ série. París: Éditions Albert Morancé, otoño-invierno 1932. pp. 20-23. Fuente: Morancé, Albert (Edit.). (otoño-invierno 1932). L'architecture vivante. París: Éditions Albert Morancé.

4. L'architecture vivante, $5^{\text {ème }}$ série. París: Éditions Albert Morancé, otoño-invierno 1932. pp. 24-27. Fuente: Morancé, Albert (Edit.). (otoño-invierno 1932). L'architecture vivante. París: Éditions Albert Morancé.

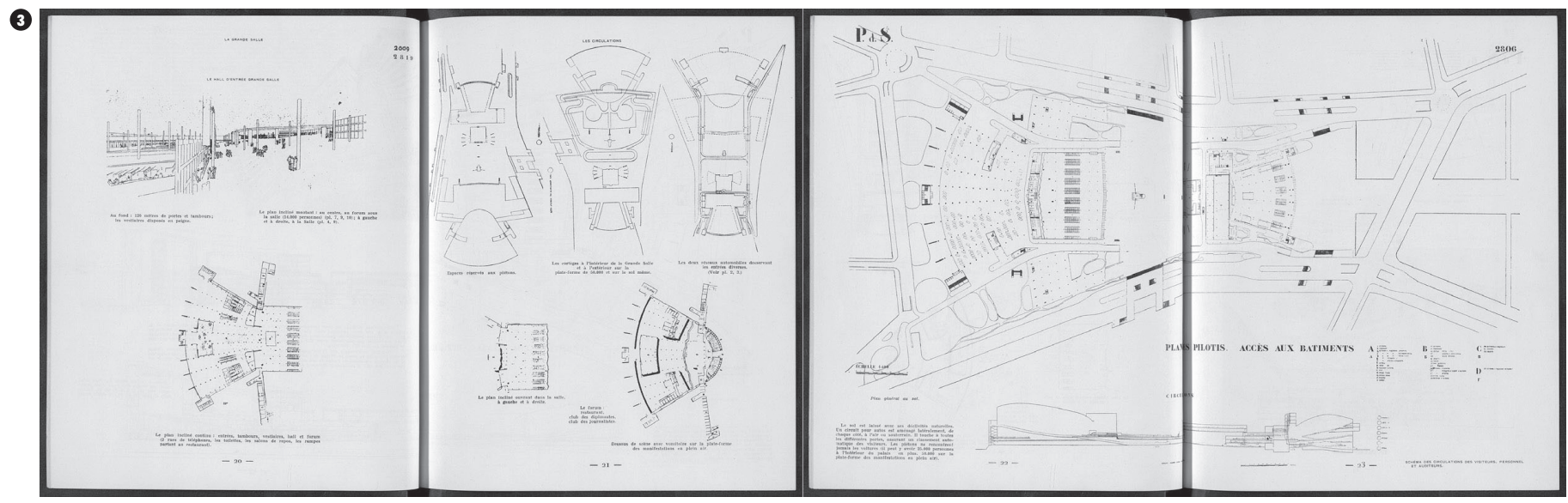

$(9$

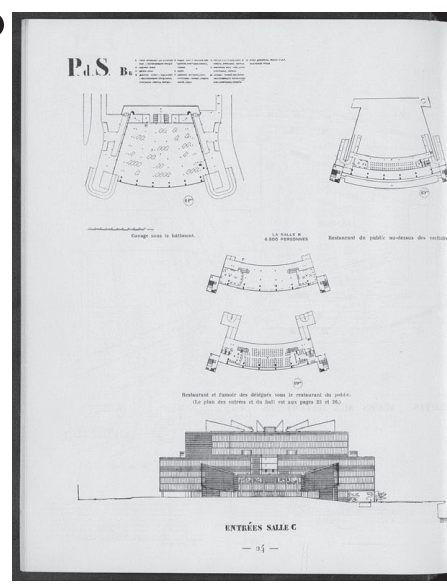

Sin duda, una página sugestiva en la que además los arquitectos añaden un párrafo inédito donde se puede leer:

El suelo se deja con sus inclinaciones naturales. Un circuito para coches se dispone lateralmente, a cada lado, al aire o subterráneo. Él toca todas las diferentes puertas, asegurando una clasificación automática de los visitantes. Los peatones no se encuentran nunca con los coches (puede haber 25.000 personas en el interior del palacio o más, 50.000 sobre la plataforma de manifestaciones al aire libre) (Morancé 1932, p. 22).

En las cuatro páginas siguientes se combinan imágenes de las dos versiones de la sala menor: la del 24 de diciembre (primer envío del concurso), donde la estructura de seis costillas soporta una cúpula abombada muy similar a la de la sala mayor; y la del 20 de enero (segundo envío), donde ya había una costilla menos y el techo, según la acústica de Gustave Lyon, se constituía como una suerte de chapa plegada más propia quizás de la arquitectura industrial que de un auditorio de congresos (FIGURA 4).

Si comenzamos desde el principio, diríamos que Le Corbusier estrena la página situando en el margen superior todas y cada una de las plantas de PdS 2811 : las cuatro de FLC 27255, correspondientes a los niveles $+11,00$ (garaje), +15,70 (restaurante público) y $+19,00$ (restaurante y fumadero de los delegados); y las tres de FLC 27235, de los niveles +32,40, $+36,00$ y $+38,40$ relativos a las piezas de administración. Bajo estas, se sitúa el alzado 
5. L'architecture vivante, $5^{\text {ème }}$ série. París: Éditions Albert Morancé, otoño-invierno 1932. pp. 28-31. Fuente: Morancé, Albert (Edit.). (otoño-invierno 1932). L'architecture vivante. París: Éditions Albert Morancé.

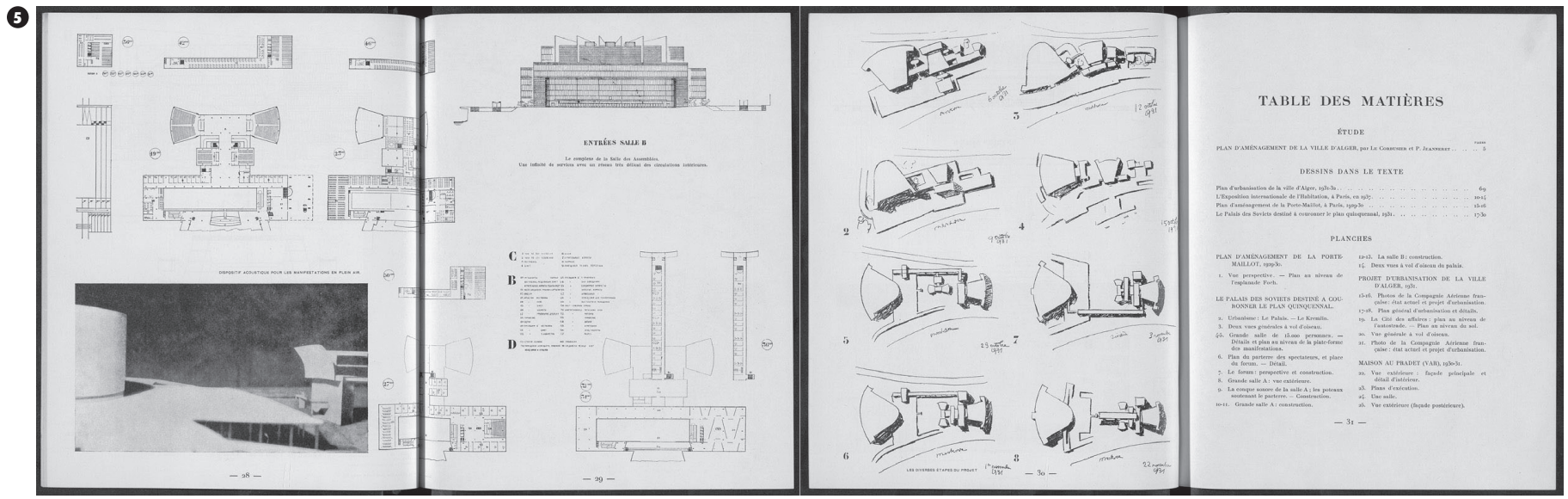

de FLC 27269 -o, PdS 2815- y una fotografía mal encuadrada que bien podría ser el recorte de otra imagen sensiblemente mayor en la que el palais se mostraba ante el objetivo como un elemento definido y bien enmarcado.

En las siguientes dos páginas de la revista, la 26 y la 27 , los arquitectos vuelven a combinar material del primer y segundo envío. Al primero pertenecerían tanto la gran perspectiva lateral de FLC 27245 -o, PdS 2817- que ocupa todo el margen inferior del pliego, como la vista interior de FLC 27244 -o, PdS 2818 - con la que Le Corbusier escribe:

El vestíbulo de acceso y el hall, verdaderas "máquinas de clasificación": las numerosas categorías de visitantes, todas viéndose mutuamente, siguen "rutas" precisas que les conducen automáticamente al destino. (Estas rutas (planos inclinados) constituyen una suerte de "rutas de montaña") (Morancé 1932, p. 26).

Al segundo envío pertenecerán, por su parte, tanto la "fachada integral (trazado definitivo), con techo acústico" situada en la parte superior de la página 27, como la "sección transversal, techo suspendido, paneles de vidrio laterales a facetas. Circulación en «rutas de montaña»" (Morancé 1932, 27) que se ubica bajo esta.
Ambos dibujos, extraídos de FLC 27746 -o, PdS 2840- (FIGURA 5).

Dejadas atrás estas cuatro páginas en las que se muestran algunos planos y fotografías de la sala B, alcanzamos otras dos hojas en las que si bien se intentan presentar las distintas plantas de la "pajarita" y el bloque de loges, en el margen superior derecha se ubicará el otro alzado transversal de la sala $B$, el que se representaba en FLC 27236, bajo el que Le Corbusier escribe: "Lo complejo de la Sala de Asambleas. Una infinidad de servicios con una red muy delicada de circulaciones interiores" (Morancé 1932, p. 29).

Mas al margen de este dibujo suelto, quién sabe si ubicado aquí para rellenar el último hueco en blanco que quedaba en el papel, en las páginas 28 y 29 Le Corbusier ubica todas y cada una de las plantas del PdS 2812: por un lado, las que se dibujaban en FLC 27253; y por el otro, las de FLC 27254. Entre estas, una imagen del "dispositivo acústico para las manifestaciones al aire libre" (Morancé 1932, 28) que adornaba el testero del bloque de administración.

Ya para finalizar, y de un modo muy similar a como aparecieran en su día durante el proyecto, esto es, como un compendio de dibujos con los que reflejar las sucesivas oscilaciones del palais, Le Corbusier ubicará en la parte final de la publicación los bocetos de las ocho etapas del proyecto. Un hecho significativo pues, si tenemos en cuenta que el esbozo es siempre la primera manifestación del arquitecto al frente del proyecto, llama la atención que Le Corbusier los ubique aquí al final; como si de nuevo quisiera demostrarnos la extraordinaria validez de su metodología. Si no, ¿̇por qué esa inesperada coincidencia entre las formas de estos "primeros" dibujos -muy probablemente realizados de un modo súbito e insconscientey las fotografías y los planos del proyecto definitivo?

Tras estos, ya solo restaba la extraña "table des matières", por costumbre siempre ubicada en la última página de la revista.

\section{ANEXO AL QUINTO NÚMERO}

La publicación, organizada a la manera de un porfolio de $28 \times 22,5 \mathrm{~cm}$ en el que se recogían los distintos textos de los artistas invitados por el director, contaba además con un anexo en el que se incluían toda una serie de "planches (láminas)" sin encuadernar -envueltas en papel de seda-que completaban la información inicial de cada una de las obras. A partir de ahí, si centramos nuestra atención en este número de 
6. Anexo de L'architecture vivante, $5^{\text {tème }}$ série. París: Éditions Albert Morancé, otoño-invierno 1932. pp. 2-5. Fuente: Morancé, Albert (Edit.). (otoño-invierno 1932). L'architecture vivante. París: Éditions Albert Morancé.

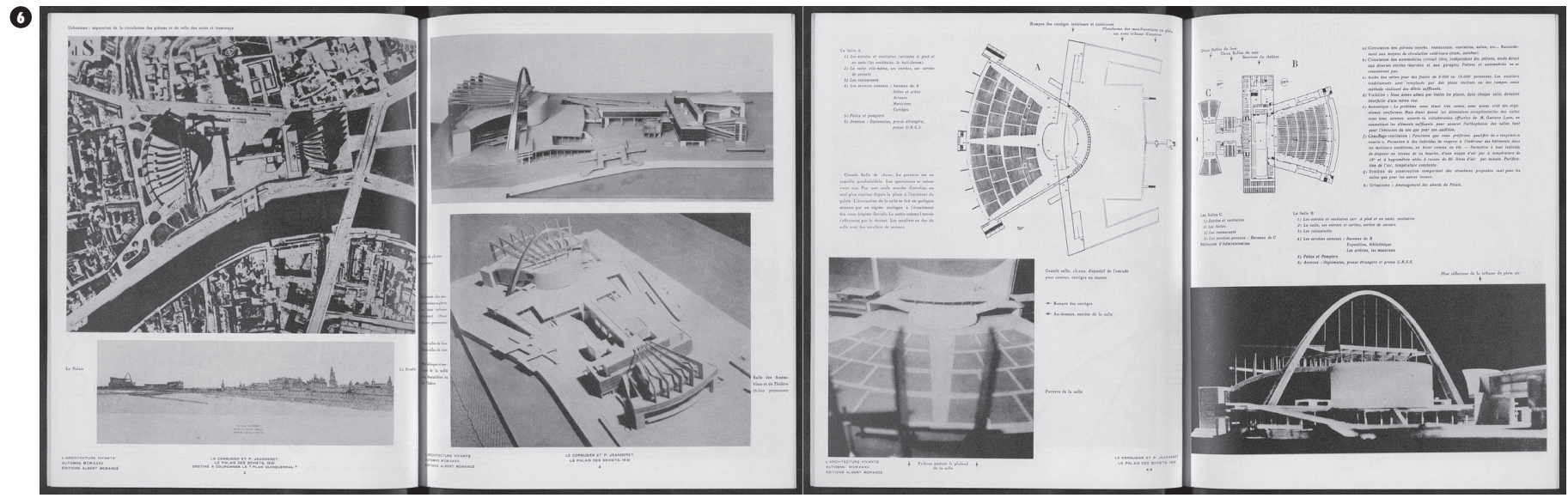

otoño-invierno de 1932 en el que Le Corbusier publica su gran palais, el anexo estaba conformado por un total de veinticinco láminas extraordinariamente confeccionadas de las que trece pertenecían a este proyecto[5].

Y decimos que bien compuestas porque a nada que las comparamos con las páginas ya vistas de la publicación en las que, como vimos en lo anterior, algunos de los elementos se encontraban desubicados, mal ordenados o fuera de escala, seremos conscientes de las verdaderas diferencias entre estas y las anteriores; como si el anexo fuera lo realmente importante de la revista. ¿̇uizás porque Le Corbusier pudiera haber participado en su maquetación de un modo mucho más activo?

Dentro del anexo, el proyecto se retoma en la página 2 con dos de los dibujos más importantes del palais: por un lado, en la parte inferior, la vista de FLC 27247 -o, PdS 2821 - donde se sombrean los contornos de los edificios -del palais y del Kremlin-con el fin de recortar sus siluetas con respecto al fondo límpido y puro de Moscú; y por el otro, en la superior, la vistosísima planta de FLC L3-1939 -0, PdS 2825- en la que se representa la "separación de la circulación de los peatones y de estos con los coches y tranvías", (Morancé 1932, p. 2 -anexo-), quién sabe si con el único propósito de certificar la perfecta comunión que en el palais existía entre la circulación de los vehículos y las personas. Si no, ¿̇por qué esa obsesión del arquitecto por combinar en el dibujo toda una infinidad de puntos delgados (peatones) con otros más gruesos (coches)? No cabe duda del interés del maestro por demostrar la extraordinaria capacidad organizativa de su palais; capaz de atender la gran escala de la ciudad junto a los escuetos reductos de su edificio (FIGURA 6).

En la otra cara de la página -la 3-, tan solo aparecerán dos fotografías generales de la maqueta, la una centrada con respecto a la otra, con las que se certifica el correcto orden de la pieza de anexo; estructurada desde lo más general a lo más particular, en contra de lo que ocurriera con las páginas propiamente dichas

[5] Además de las trece láminas de "El Palacio de lo Soviets destinado a coronar el Plan Quinquenal", el anexo de este número de la revista contaba además con un plano del Plan d'aménagement de la Porte-Maillot (1929-30), siete del Projet d'urbanisation de la ville d'Alger (1931) y cuatro de la Maison au Pradet (1930-31). Véase la "table des matières" de la página 31 . 
7. Anexo de L’architecture vivante, $5^{\text {ème }}$ série. París: Éditions Albert Morancé, otoño-invierno 1932. pp. 6-9. Fuente: Morancé, Albert (Edit.). (otoño-invierno 1932). L’architecture vivante. París: Éditions Albert Morancé.

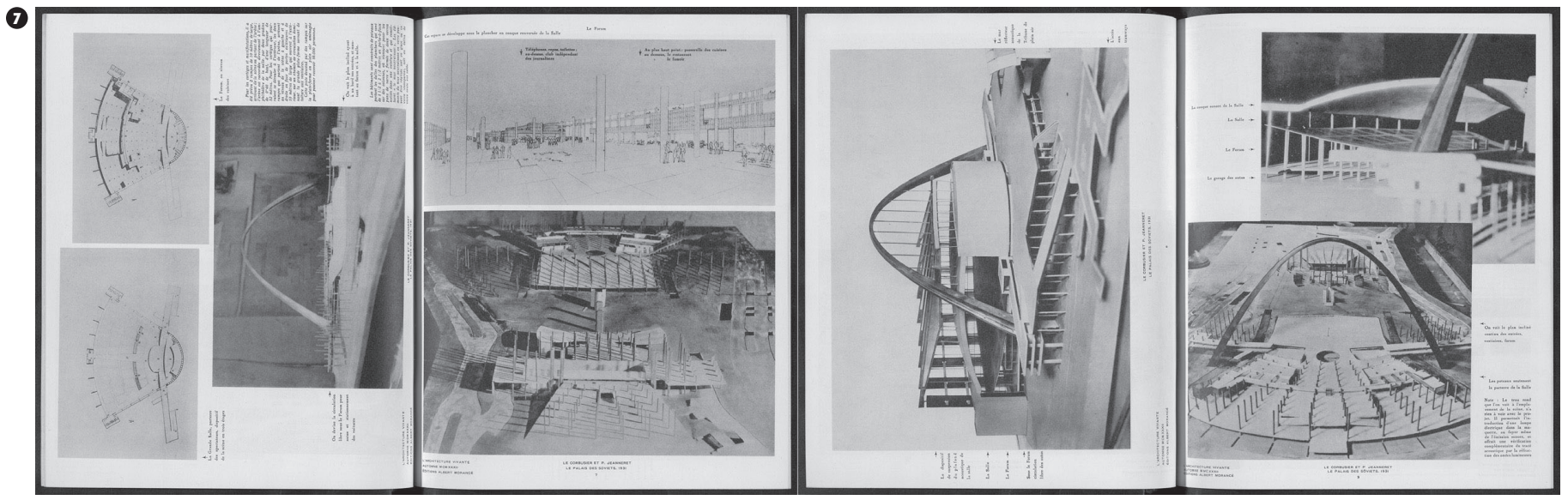

Así, si continuamos ahora con las páginas 6 y 7 , veremos que en ellas los arquitectos modifican la orientación de las láminas -la izquierda en horizontal y la derecha en vertical- para un mejor aprovechamiento del papel. De hecho, gracias a ello, se logran encajar sobre la fotografía las dos plantas (de nuevo sombreadas) de PdS 2810: la de FLC 27234, relativa a "la Gran Sala, [el] patio de butacas de los espectadores, [y el] dispositivo del escenario en tres plantas"; y la de FLC 27270, donde se resaltan algunas de las piezas de "el Forum al nivel de las cocinas" (Morancé 1932, p. 6 -anexo-). Todo ello, acompañado de un extracto del primer capítulo de la memoria en el que se podía leer:

Para las comitivas y manifestaciones, se han previsto 2 rampas de 10 metros de ancho, que llegan del escenario o que parten de la palestra; la palestra está directamente conectada con el anfiteatro de la sala, por dos niveles de 0,40 m de alto, y una longitud de 52 metros. Para las comitivas que podrían desarrollarse en el exterior, las dos rampas que parten desde la palestra, llegan al nivel del escenario a izquierda y derecha, frente a las puertas exteriores de 10 metros de ancho que abren hacia el exterior, sobre un camino de circulación que domina la gran plataforma que sirve de techo a los guardarropas.
Esta pista desciende por rampas, sobre la plataforma al aire libre habilitada para poder recibir a 50.000 personas (Morancé 1932, p. 6 -anexo-).

Bajo las plantas, y ocupando el centro de la página, aparece una fotografía del gran arco parabólico sobrevolando la maqueta desmontada del palais. Una imagen importante que pone de manifiesto una vez más el alto grado de independencia (constructiva) entre el uno y el otro; como si el arco, a la manera de una pieza acabada en sí misma, pudiera subsistir con independencia del estado en el que se encontrase el edificio.

No con mucha relación con lo que se muestra en la fotografía, los arquitectos añaden otro nuevo párrafo esta vez sacado del capítulo sexto de la memoria, en el que se puede leer:

Los edificios están construidos con pilares que soportan losas de 1,5 a 2,5 metros de vuelo sobre las columnas, donde se colocan los paños de vidrio "formados por dos vidrios sellados por un cinturón hasta constituir el "muro neutralizante". Los elementos del muro neutralizante en vidrio pueden estar realizados en cristal o vidrio transparente, o en planchas de vidrio colado de arena (Morancé 1932, p. 6 -anexo-).
Por su parte, las dos imágenes de la lámina 6 podríamos decir que complementan la información aportada por la 5. De nuevo la vista interior de FLC 27250 -o, PdS 2820- en la que se observa el espacio interior del Forum, al que se hacía referencia con las plantas anteriores, y una nueva fotografía de la maqueta (desmontada), esta vez tomada desde el aire, con la que se puede observar la estrecha relación que existía entre el ondulante plano del suelo de Moscú y las disciplinadas piezas del palais; a todos los efectos viables por la infinita precisión de sus pilotis.

En tanto que como continuación de las anteriores, las siguientes dos láminas del anexo -la 8 y la 9- se organizarán del mismo modo que sus predecesoras, esto es, la izquierda en horizontal y la derecha en vertical. En ellas, los arquitectos tan solo ubicarán tres fotografías de la maqueta: una desde el exterior, donde de nuevo se observa el aspecto general de la sala A con todas y cada una de sus piezas; y dos del modelo desmontado -la una sin el pan de verre de la fachada y la otra tan solo en pilotis-, quizás para explicar lo que se escribe a través de una nota de esta misma lámina 9 , donde se podía leer:

El agujero redondo que se observa en la posición del escenario, no tiene nada que 
8. Anexo de L'architecture vivante, $5^{\text {ème }}$ série. París: Éditions Albert Morancé, otoño-invierno 1932. pp. 10-13. Fuente: Morancé, Albert (Edit.). (otoño-invierno 1932). L'architecture vivante. París: Éditions Albert Morancé.

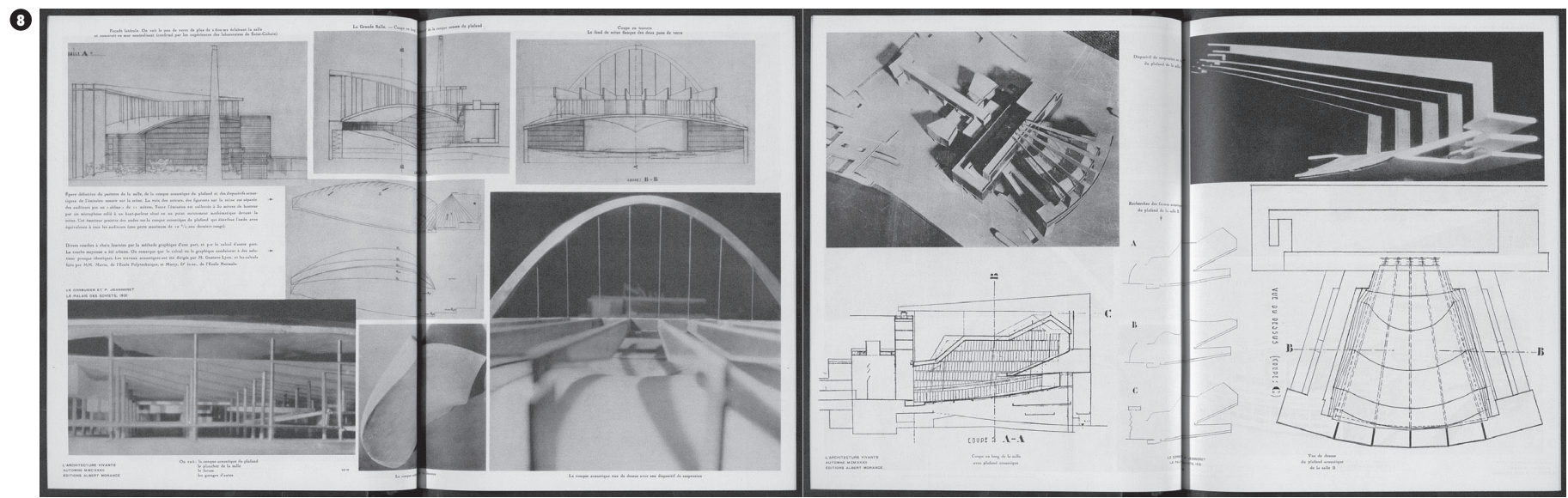

ver con el proyecto. Permitía la introducción de una lámpara eléctrica en la maqueta, en el foco mismo de la emisión sonora, y ofrecía una verificación complementaria del trazado acústico por la refracción de las ondas luminosas (Morancé 1932, p. 9 -anexo-).

Dejadas atrás estas dos sencillas láminas que sirven de complemento a las dos anteriores, es momento de situarse ante las que posiblemente fueran las páginas más abigarradas del anexo, la 10 y la 11; maquetadas de manera conjunta y con las que se pretende dar por cerrada la información relativa a la sala A (FIGURA 8).

Entre planos y fotografías, los arquitectos incluirían en estas dos láminas un total de siete imágenes de aquella versión (definitiva) de la sala A dibujada por vez primera en el alzado y las secciones de FLC 27789 y 27788 -o, PdS 2841 -. Sin duda, tres dibujos importantes que los arquitectos ubican en la parte superior de la página y de los que escriben:

Diseño definitivo del patio de butacas de la sala, de la concha acústica del techo y de los dispositivos acústicos de emisión sonora sobre el escenario. La voz de los actores, de los figurantes sobre el escenario, está separada de los oyentes por un "abismo" de 11 metros. Toda la emisión es recogida a 30 metros de altura por un micrófono conectado a un altavoz situado en un punto estrictamente matemático frente al escenario. Este emisor proyecta ondas sobre la concha acústica del techo que distribuye la onda con equivalencia a todos los oyentes (una pérdida máxima del 10\% en las últimas filas) (Morancé 1932, p. 10 -anexo-).

Además de estos tres planos de PdS 2841 que ocupan todo el margen superior-reforzados a su vez por las tres fotografías de debajo en las que se replican algunos de estos mismos puntos de vista-, en el centro del pliego los arquitectos añadirán para concluir la curva de FLC 27239 -o, PdS 2826- en la que se detalla la radiación sonora sobre la sección definitiva de la sala y el compendio de alternativas de FLC 27240 -o, PdS 2827-. Un aspecto también explicado en otro de los párrafos de la lámina, donde se podía leer:

Distintas curvas a elegir producidas por el método gráfico por un lado, y por el cálculo por el otro. La curva media ha sido admitida. Se observa que el cálculo y lo gráfico conducen a soluciones casi idénticas. Los trabajos acústicos han estado dirigidos por el Sr. Gustave Lyon, y los cálculos hechos por MM. Morin, de la Escuela Politécnica, y Marty, doctor en ciencias, de la Escuela Normal (Morancé 1932, p. 10 -anexo-).

Con el permiso de la plache final en la que se ubicarán dos fotografías generales de la maqueta, no podemos por menos de afirmar que las láminas 12 y 13 relativas a la sala $B$ son las últimas que este número concreto de L'architecture vivante dedica al palais (FIGURA 9).

A partir de aquí, que tan solo existan dos planches dedicadas a la sala $B$ frente a las seis de la sala $A$, obedece al hecho de que de las catorce páginas que la revista dedicaba al palais, seis habían sido ocupadas por planos y fotografías de esta sala. De ahí que los arquitectos apenas tuvieran material para componer alguna otra lámina del anexo; tan solo una vista aérea en la que además se incluyen el bloque de loges, la "pajarita" y la pieza de administración, y una fotografía inédita en la que se nos enseña el "dispositivo de suspensión en balanza del techo" (Morancé 1932, 13 -anexo-). Bajo estas, la planta (desproporcionada) y la sección que quedaban por utilizarse de la modificación de FLC 27746 -0, PdS 2840-, y las tres alternativas acústicas pasadas a limpio en FLC 27241 -o, PdS 2828-. 
9. Anexo de L'architecture vivante, $5^{\text {ème }}$ série. París: Éditions Albert Morancé, otoño-invierno 1932. p. 14. Fuente: Morancé, Albert (Edit.). (otoño-invierno 1932). L'architecture vivante. París: Éditions Albert Morancé.

Ya para finalizar, y tal y como decíamos en lo anterior, los arquitectos cerrarán la última página de este primer capítulo del proyecto con dos fotografías generales de la maqueta y un pequeño texto de apenas un par de líneas en las que se hace referencia a uno de los innumerables experimentos llevados a cabo sobre el palais, el de sus controvertidos verres hermétiques utilizados a duras penas en el Centrosoyus:

El Palacio entero está concebido en "muros neutralizantes"; los paños de vidrio herméticos han proporcionado un módulo único de 3,50 x 1,10 m con circuito de aire caliente o frío al interior. Los múltiples ensayos de los laboratorios St-Gobain han confirmado la teoría conocida como "respiración exacta" con "muros neutralizantes" (Morancé 1932, p. 14 -anexo-).

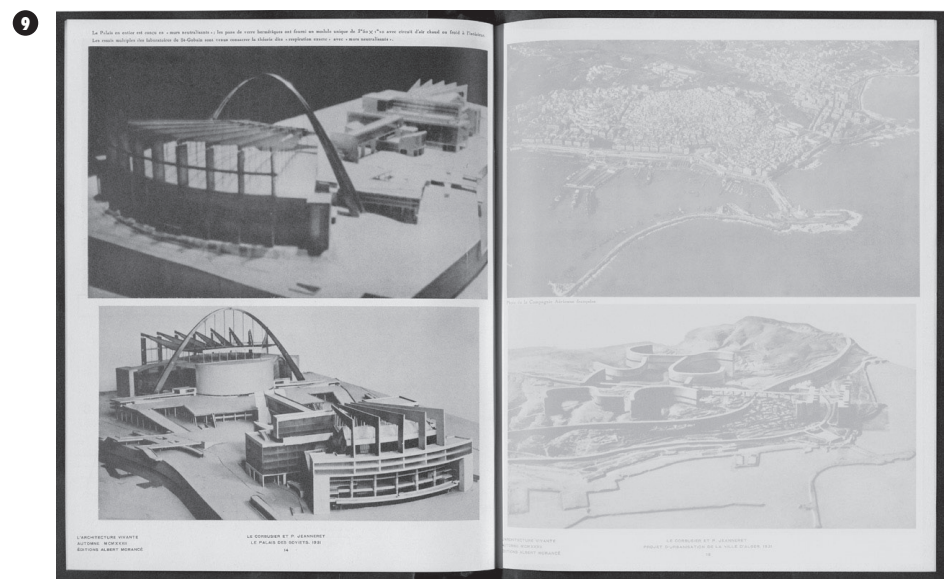

\section{CONCLUSIÓN}

Situándonos como meros observadores externos, el escrito no pretende otra cosa que desvelar algunos de los entresijos más desconocidos de la original reconstrucción que Le Corbusier realiza sobre la revista. De ahí que, gracias al "papel" logramos refrendar la esencia del trabajo corbusieriano, pues żqué es sino lo principal lo que el maestro publica, en esta primera ocasión, sobre el Palacio de los Soviets? En este sentido, fundamentales resultan las asociaciones de planos y fotografías que se dan a lo largo de las páginas.

Es él mismo quien, sin duda, nos desvela el material más importante del palais; también algunas de sus técnicas de representación más comunes, como los vistosos sombreados en negro -realizados expresamente para las publicacionescon los que se añade profundidad a los planos, o las célebres axonometrías interiores donde, como decíamos, se combinan dos tipos de trazado: el dibujo lineal, hecho a regla, para representar el espacio de la arquitectura; y el curvo, ya a mano alzada, con el que se reproducen sus personajes.

Es por tanto gracias a este proyecto y su representación sobre "el papel" como logramos entender-tras enunciar los escritos de presentación- la verdadera filosofía de aquella architecture vivante añorada por Perret y los directores de la revista. Y es que, para ellos, qué era esto sino el resultado de la estrecha relación que siempre debía darse entre forma y función, esto es, entre las libertades artísticas del arquitecto y las restricciones más comunes de la arquitectura. Así, qué proyecto será más adecuado que este Palacio de los Soviets de Le Corbusier (y Pierre) para responder a aquella filosofía inicial de la revista; donde apenas se pretendía otra cosa que mostrar "los fecundos recursos del artista contemporáneo, de su claridad de espíritu, de su juicio delicado y seguro".

Pero las publicaciones son además para el maestro útiles medios de denuncia y protesta. De ahí que intencionadas sean, por tanto, ediciones como esta de la de L'architecture vivante donde Le Corbusier nos muestra su proyecto de un modo triunfal y victorioso; como si hubiera sido este $-y$ no otro- el flamante ganador de aquel aciago concurso de finales de 1931.

A partir de aquí, otras siete publicaciones mostrarán este importante edificio bajo el beneplácito de su arquitecto: Cahiers d'art $\mathrm{n}^{\circ}$ 1-2 (1932), L'architecture d'aujourd'hui n ${ }^{\circ} 10$ (1933) -también en el $2^{\circ}$ número especial de abril de 1948-, OEuvre complète 1929-1934 (1934), New world of space (1948), L'atelier de la recherche patiente (1960) y Aujourd'hui. Art et architecture $\mathrm{n}^{\circ} 51$ (1965).

Tras este 1965, casi alcanzados los 78 años, el arquitecto desaparece.

\section{BIBLIOGRAFÍA}

Bloc, André (Dir.). (1933). L'architecture d'aujourd'hui $n^{\circ}$ 10. París: Éditions Boulogne sur Seine.

Bloc, André (Dir.). (abril de 1948). L'architecture d'aujourd'hui. París: Éditions Boulogne sur Seine.

Bloc, André (Dir.). (noviembre de 1965). Aujourd'hui. Art et architecture, 9ème année. París: Éditions Boulogne sur Seine.

Boesiger, Willy (Edit.). (1934). OEuvre complète 19291934. Zúrich: Girsberger.

Le Corbusier. (1948). New world of space. Nueva York: Éditions Reynal \& Hitchcock.

Le Corbusier. (1960). L'atelier de la recherche patiente. París: Éditions Vincent, Fréal \& Cie.

Morancé, Albert (Edit.). (otoño-invierno 1923). L'architecture vivante. París: Éditions Albert Morancé

Morancé, Albert (Edit.). (otoño-invierno 1932). L'architecture vivante. París: Éditions Albert Morancé

Valéry, Paul. (1923). Eupalinos o el arquitecto. París: Éditions Gallimard-Verlag.

Zervos, Christian (Dir.). (1932). Cahiers d'art nº-2. París: Éditions Cahiers d'art. 